\title{
The quest for optimal and reliable guidelines based on robust evidence for the treatment of cholangiocarcinoma
}

\author{
Daniel Azoulay ${ }^{1}$, David Bomze ${ }^{2}$, Tomer Meirson ${ }^{3,4}$ \\ ${ }^{1}$ Centre Hépato-Biliaire, Assistance Publique-Hôpitaux de Paris, Hôpital Universitaire Paul Brousse, Institut National de la Santé et de la Recherche \\ Médicale (INSERM) Unité 935, and Université Paris-Saclay, Villejuif, France; ${ }^{2}$ Sackler Faculty of Medicine, Tel Aviv University, Tel Aviv, Israel; \\ ${ }^{3}$ Ella Lemelbaum Institute for Immuno-oncology, Sheba Medical Center, Ramat-Gan, Israel; ${ }^{4}$ The Azrieli Faculty of Medicine, Bar-Ilan University, \\ Safed, Israel \\ Correspondence to: Daniel Azoulay. Centre Hépato-Biliaire Assistance Publique-Hôpitaux de Paris, Hôpital Universitaire Paul Brousse, 12 Avenue \\ Paul Vaillant Couturier, F-94804 Villejuif, France. Email: daniel.azoulay@aphp.fr. \\ Comment on: Gavriilidis P, Askari A, Roberts KJ, et al. Appraisal of the current guidelines for management of cholangiocarcinoma-using the Appraisal \\ of Guidelines Research and Evaluation II (AGREE II) Instrument. Hepatobiliary Surg Nutr 2020;9:126-35.
}

Submitted Mar 16, 2021. Accepted for publication Apr 15, 2021.

doi: $10.21037 / \mathrm{hbsn}-21-117$

View this article at: https://dx.doi.org/10.21037/hbsn-21-117

In 1991, Gordon H. Guyatt described the evidencebased medicine (EBM) as "a focus on educating frontline clinicians in assessing the credibility of research evidence, understanding the results of clinical studies, and determining how best to apply the results to their everyday practice" (1).

In 2010, Graham et al. defined clinical guidelines as "statements that include recommendations intended to optimize patient care that are informed by a systematic review of the evidence and an assessment of the benefits and harms of alternative care options" (2). Since 2010, the number of clinical guidelines increased exponentially, and the query on PubMed with the term "new guidelines" produces 59,773 results.

In the field of oncology, the systematic review of the evidence has specific and formal rules (3).

Traditional hierarchies place systematic reviews and meta-analyses followed by randomized trials at the top of the evidence pyramid and are used for developing clinical guidelines. The development of guidelines is a tremendous endeavor: the National Institute for Health and Care Excellence (NICE framework) guide manual (199 pages, available online) to develop guidelines counts no less than 48 steps and mandates a guideline update every 3 years.

Notwithstanding, the validity of the recommendations of clinical practice guidelines depends upon the quality of the methodology used to create them.
The Appraisal of Guidelines for Research and Evaluation (AGREE II) instrument is acknowledged as the most adapted tool (out of more than available 40 tools) to appraise clinical practice guidelines (4). The AGREE II tool includes 23 items divided into six domains: scope and purpose, stakeholder involvement, the rigor of development, clarity of presentation, applicability and editorial independence. Each domain score is calculated according to an adapted formula (https://www.agreetrust.org) and a guideline with a score $>80 \%$, upon overall appraisal, can be considered applicable without modifications. The polychotomous nature of the AGREE checklist giving equal importance to all of its domains is the main weakness of this tool: whether all items and domains contribute equally to the quality of a guideline remains unclear.

Recently in this journal, Gavriilidis et al. (5), using the AGREE II instrument, reported the first appraisal of the current guidelines for the management of cholangiocarcinoma (CC). The main results of their research are as follows:

(I) Thirteen such guidelines are available;

(II) The guidelines scored poorly for applicability $(13 \%)$, the rigor of development $(30 \%)$, and stakeholder involvement (39\%);

(III) None of the 13 guidelines was recommended universally for use without modification;

(IV) The conclusion of the authors is unambiguous 
and without appeal: "Overall, the methodological quality of guidelines on the surgical management of cholangiocarcinoma is poor".

This type of conclusion of guidelines appraisal is common: the quality scores as measured with the AGREE Instrument have remained moderate to low over the last two decades in general (6) and specifically in the field of liver tumors (7-9). In brief, most often, "guidelines do not fulfill the guidelines to build them".

So far, well-conducted randomized controlled trials (RCTs) remain the gold standard of objective clinical research and have the highest level of evidence in the GRADE system (10).

Only 11 RCTs are available in the field of CC because the recruitment of a sufficient number of patients within a reasonable period of time is difficult due to the rarity of the disease and, further, to palliate the latter, these studies often mix patients with three genuinely different diseases (intrahepatic CC, peri-hilar cancer and CC of the main bile duct). In this journal, Horesh et al. (11) tackle the robustness of RCTs in the field of CC using three main tools: (I) the survival-inferred fragility index (SIFI, the minimum number of reassignments of the best survivors between arms that would overturn the statistical outcomes); (II) the restricted mean survival time (RMST) difference to evaluate the gain in survival; (III) the level of spin in inconclusive studies to assess distorted reporting strategies. Here also, the conclusion of the authors is unambiguous and without appeal: "RCTs regarding the treatment of CC showed a low degree of robustness with a frequent proportion of associated spin".

In conclusion, the quest for developing guidelines based on robust evidence via well-conducted RCTs and applicable in real-life remains ongoing in the field of CC management. We hope that our community will succeed in running the two hares simultaneously for the best of our patients.

\section{Acknowledgments}

Funding: None.

\section{Footnote}

Provenance and Peer Review: This article was commissioned by the editorial office, Hepatobiliary Surgery and Nutrition. The article did not undergo external peer review.

Conflicts of Interest: All authors have completed the ICMJE uniform disclosure form (available at https://hbsn. amegroups.com/article/view/10.21037/hbsn-21-117/coif). The authors have no conflicts of interest to declare.

Ethical Statement: The authors are accountable for all aspects of the work in ensuring that questions related to the accuracy or integrity of any part of the work are appropriately investigated and resolved.

Open Access Statement: This is an Open Access article distributed in accordance with the Creative Commons Attribution-NonCommercial-NoDerivs 4.0 International License (CC BY-NC-ND 4.0), which permits the noncommercial replication and distribution of the article with the strict proviso that no changes or edits are made and the original work is properly cited (including links to both the formal publication through the relevant DOI and the license). See: https://creativecommons.org/licenses/by-nc-nd/4.0/.

\section{References}

1. Djulbegovic B, Guyatt GH. Progress in evidence-based medicine: a quarter century on. Lancet 2017;390:415-23.

2. Graham R, Miller Wolman D, Greenfield S, et al. Clinical practice guidelines we can trust. Institute of Medicine (US) Committee on Standards for developing trustworthy clinical practice guidelines. Washington (DC): The National Academies press (US); 2011.

3. Loblaw DA, Prestrud AA, Somerfield MR, et al. American Society of Clinical Oncology Clinical Practice Guidelines: formal systematic review-based consensus methodology. J Clin Oncol 2012;30:3136-40.

4. Coroneos CJ, Voineskos SH, Cornacchi SD, et al. Users' guide to the surgical literature: how to evaluate clinical practice guidelines. Can J Surg 2014;57:280-6.

5. Gavriilidis P, Askari A, Roberts KJ, et al. Appraisal of the current guidelines for management of cholangiocarcinomausing the Appraisal of Guidelines Research and Evaluation II (AGREE II) Instrument. Hepatobiliary Surg Nutr 2020;9:126-35.

6. Alonso-Coello P, Irfan A, Solà I, et al. The quality of clinical practice guidelines over the last two decades: a systematic review of guideline appraisal studies. Qual Saf Health Care 2010;19:e58.

7. Holvoet T, Raevens S, Vandewynckel YP, et al. Systematic review of guidelines for management of intermediate hepatocellular carcinoma using the Appraisal of Guidelines Research and Evaluation II instrument. Dig Liver Dis 
2015;47:877-83.

8. Gavriilidis P, Roberts KJ, Askari A, et al. Evaluation of the current guidelines for resection of hepatocellular carcinoma using the Appraisal of Guidelines for Research and Evaluation II instrument. J Hepatol 2017;67:991-8.

9. Bastiaenen VP, Hovdenak Jakobsen I, Labianca R, et al. Consensus and controversies regarding follow-up after treatment with curative intent of nonmetastatic colorectal cancer: a synopsis of guidelines used in countries represented in the European Society of Coloproctology.

Cite this article as: Azoulay D, Bomze D, Meirson T. The quest for optimal and reliable guidelines based on robust evidence for the treatment of cholangiocarcinoma. HepatoBiliary Surg Nutr 2021;10(6):913-915. doi: 10.21037/ hbsn-21-117
Colorectal Dis 2019;21:392-416.

10. Bothwell LE, Greene JA, Podolsky SH, et al. Assessing the Gold Standard--Lessons from the History of RCTs. N Engl J Med 2016;374:2175-81.

11. Horesh N, et al. Assessment of Robustness of Randomized Controlled Trials for the Treatment of Cholangiocarcinoma in Three domains: Survival-Inferred Fragility Index, Restricted Mean Survival Time, and the Spin Effect. Hepatobiliary Surg Nutr [Epub ahead of print]. doi: 10.21037/hbsn-21-118 